\title{
Perioperative Use of Intravenous Magnesium Sulfate to Decrease Postoperative Pain
}

\author{
Dr. Tracy Beckham*, CRNA, DNAP \\ Missouri State University, Springfield, USA
}

Submission: February 01, 2020; Published: February 18, 2020

*Corresponding author: Tracy Beckham, Missouri State University, Springfield, USA

\begin{abstract}
Anesthesia providers currently use non-opioid medications in the effort to decrease opioid use. In a randomized controlled trial in 1996, it was first discovered that magnesium sulfate decreased postoperative pain. Further studies from 2013 until 2018 compared intravenous magnesium sulfate versus placebo to decrease postoperative pain. These included five systematic reviews, seven randomized controlled trials (RCTs), and one review article which included 5,858 patients. The data gained from these articles was condensed into information for anesthesia providers so they would be able to safely utilize magnesium sulfate to decrease postoperative pain, which could lead to decreased opioid utilization.

Keywords: Magnesium sulphate; Intravenous; Postoperative pain; Anesthesia; Perioperative; Intraoperative; opioid

Abbreviations: CDC: Centers for Disease Control and Prevention; RCTs: Randomized Controlled Trials; RDAs: Recommended Dietary Allowances; NMDA: N-methyl-D-aspartate amino acid; IV: Intravenous; mg: Milligram; kg: Kilogram; ml: Milliliter; VAS: Visual Analog Scale
\end{abstract}

\section{Introduction}

Deaths related to opioid overdose have reached epidemic proportions over the last decade, which has created interest in finding ways to decrease perioperative opioid use. The Centers for Disease Control and Prevention (CDC) reported 42,249 overdose deaths from opioids, prescription and illicit, in 2016 out of a total of 63,632 . This accounts for $66 \%$ of overdose deaths [1]. Additionally, the CDC reported that over $40 \%$ $(16,899$ lives) of the overdose deaths from opioids actually involved prescription opioids and resulted in 46 deaths per day [1]. Opioid abuse, opioid addiction, and opioid deaths have caused renewed focus on treating postoperative pain with either decreased amounts of opioids or no opioids at all. Anesthesia providers are performing opioid free anesthesia intraoperatively. One of the medications that has a renewed focus in controlling postoperative pain is IV magnesium sulfate. There is adequate evidence from randomized controlled trials, systematic reviews, and meta-analyses that IV magnesium sulfate has proven efficacy in decreasing postoperative pain scores, which has led to decreased postoperative opioid use. However, many anesthesia providers do not yet know currently recommended IV magnesium sulfate doses for postoperative pain control, common side effects of magnesium sulfate, or are concerned about hypermagnesemia. Magnesium is an intracellular ion that is an essential mineral involved in more than 300 biochemical reactions, some of which regulate muscle and nerve function, regulate blood pressure and blood sugar levels, and make proteins, bone, and DNA [2,3]. Daily Recommended Dietary Allowances (RDAs) for magnesium in the adult male population from ages $19-30$ years is $400 \mathrm{mg}$, and over age 31 is $420 \mathrm{mg}$. The adult female RDA for magnesium is $310 \mathrm{mg}$ for years $19-30$ and $320 \mathrm{mg}$ for over 31 [4]. According to a study by Rosanoff, Weaver, and Rude in 2012, $48 \%$ of the United States population in 2005-2006 consumed less than the RDA for magnesium [5]. Lambe et al. reported in 2016 that low preoperative levels of magnesium can be further decreased by surgical stress, which can lead to symptomatic magnesium deficiency, increased morbidity, and longer recovery times [6]. Magnesium levels are not routinely checked preoperatively, even though statistics show magnesium consumption in the United States is low, and many patients may have low blood levels of magnesium before their surgical procedure. IV magnesium sulfate is commonly used in the United States to treat pre-eclampsia, 
eclampsia, and Torsade De Pointes. Common dosing of magnesium sulfate for treating pre-eclampsia and eclampsia are a loading dose of 4 to $6 \mathrm{~g}$, followed by a maintenance infusion of $1-2 \mathrm{~g}$ per hour [7]. The bolus doses of 4 to $6 \mathrm{~g}$ consistently doubled the baseline serum magnesium concentrations one half hour after a bolus [7]. The typical bolus dose for Torsade De Pointes is $2 \mathrm{~g}$ (25-50mg/ $\mathrm{kg}$ in children) over 1 to 2 minutes [8]. IV magnesium sulfate doses used in studies researching postoperative pain and opioid use were lower than the dosages used to treat pre-eclampsia and eclampsia. Anesthesia providers need to be informed on how to use IV magnesium sulfate to decrease intraoperative pain and postoperative pain, leading to a goal of a decrease in overall opioid use. For pain control, Magnesium sulfate has been found to non-competitively inhibit N-methyl-D-aspartate amino acid (NMDA) receptors in the central nervous system, which has been associated with altered pain perception [9-11]. The mechanism of action for magnesium sulfate is blocking the flow of $\mathrm{Na}+, \mathrm{K}+$, and $\mathrm{Ca}+$ in a voltage-gated manner within the channel of the NMDA receptor. This mechanism of action and site of action is different from noncompetitive antagonists such as Ketamine, MK-801, and phencyclidine [12].

The first randomized clinical trial (RCT) using magnesium sulfate to control postoperative pain occurred in 1996 which found a $20 \%$ magnesium $15 \mathrm{ml}$ bolus before start of surgery followed by a $2.5 \mathrm{ml} / \mathrm{h}$ for $20 \mathrm{~h}$ infusion led to decreased morphine consumption, less discomfort, and better sleep quality postoperatively for abdominal hysterectomy patients [13]. Following this original study, further research has studies various administration routes of magnesium sulfate, such as topical, intrathecal, epidural, and IV via a peripheral intravenous catheter. An IV bolus and/or infusion via a peripheral intravenous catheter has been the most studied route and generally the focus for anesthesia providers. The first systematic review (SR) and meta-analysis of the literature comparing peri-operative intravenous administration of magnesium sulphate to placebo for postoperative pain control was published by Albrecht, et al. in 2012 [14]. This SR included 1,461 patients, with $48 \%$ involving abdominal surgery, $24 \%$ having hysterectomies, and $24 \%$ having orthopedic surgery. Six of the studies used a single bolus, 15 studies used a bolus followed by an infusion, and two included infusions only. Two studies combined magnesium sulfate and tramadol in patientcontrolled analgesia pumps and two other studies administered Magnesium via spinal. Excluding the two spinal route studies, the most common bolus doses in this study ranged between 30 $50 \mathrm{mg} / \mathrm{kg}$. Infusion rates with or without a bolus ranged from as low as $6 \mathrm{mg} /$ hour up to $500 \mathrm{mg}$ /hour. The total 24-hour doses of magnesium ranged from $3 \mathrm{~g}$ to $16.3 \mathrm{~g}$. The meta-analysis showed an overall reduction in Morphine consumption at 24 hours postoperatively in the Magnesium groups by an average of $24.4 \%$ compared to placebo, suggesting lower postoperative pain scores. In addition, there was no statistically significant difference in cumulative morphine consumption between the various dosing regimens of bolus only, bolus plus infusion, or infusion only. Lastly, there was no correlation between the total dose of magnesium administered and a reduction of morphine consumption at 24 hours postoperatively, suggesting that increasing the amount of magnesium given did not have a statistically significant decrease in morphine consumption. Three additional systematic reviews have since supported the use of intravenous magnesium sulfate to decrease postoperative pain. The first meta-analysis was done by De Oliveira et al. in 2013 and included 20 randomized clinical trials with 1,257 subjects [15]. They found that IV magnesium decreased postoperative pain both at rest and with movement at 24 hours postoperatively. The data additionally showed that there was a large decrease in opioid consumption for the magnesium treatment group versus placebo. The majority of the trials in this meta-analysis used a bolus dose of 30-50 mg along with an infusion ranging from $0.5 \mathrm{mg} / \mathrm{kg}$ over 20 hours up to $500 \mathrm{mg}$ per hour for 20 hours. The most common intraoperative infusion rate reported was $8-15 \mathrm{mg} / \mathrm{kg} /$ hour. The second meta-analysis of IV administration of magnesium sulfate was by published by Guo et al. in 2015 and focused on postoperative opioid requirements, pointing to less postoperative pain [16]. This provided further evidence that perioperative administration of IV magnesium sulfate significantly reduced postoperative pain at rest, postoperative pain with movement 24 hours postoperatively, and reduced postoperative analgesic consumption in urogenital, orthopedic, and cardiovascular surgeries versus placebo. However, the data was not conclusive regarding analgesic consumption and gastrointestinal surgery. This review included twenty-seven RCTs involving 1,504 patients which included six studies that utilized a bolus of magnesium, eighteen studies that utilized a bolus and infusion, and three studies that only used an infusion of magnesium. Twenty-one of the studies utilized boluses and or infusion only during the surgical time, as opposed to running the infusion for a specified length of time. The most common dosing regimens were again a bolus of $30-50 \mathrm{mg} / \mathrm{kg}$ and the infusion rates most commonly used were $8-15 \mathrm{mg} / \mathrm{kg} /$ hour. Three studies utilized $500 \mathrm{mg} /$ hour post-bolus for the infusion rate. Finally, the third systematic review with metaanalysis was published by Arumugam, Lau, and Chamberlain in 2016 which further provided evidence on the postoperative pain control efficacy of intravenous magnesium sulfate [17]. The data for this analysis came from 14 RCTs containing 910 patients. Thirteen out of the 14 studies showed a significant decrease in postoperative opioid consumption. One study only used a bolus, six studies used only a continuous infusion, and the remaining seven studies used a bolus and infusion combination. Bolus 
doses were not provided, and the most common infusion doses associated with an unspecified bolus dose were either $10 \mathrm{mg} /$ $\mathrm{kg} /$ hour or $500 \mathrm{mg} /$ hour. A subgroup analysis of the types of surgeries found that cholecystectomy, colorectal, coronary artery bypass, abdominal hysterectomy, and prostatectomy surgeries significantly reduced morphine consumption postoperatively while thoracotomy, infra-umbilical and orthopedic surgeries did not show a similar significant reduction. These results were contrary to the results published by Guo which provided evidence for efficacy of magnesium sulfate in orthopedic procedures and inconclusive results for gastrointestinal surgeries. A further subgroup analysis of the time of magnesium administration found that administering magnesium intraoperatively or in combination of intraoperatively and postoperatively showed a significant reduction in morphine consumption postoperatively while only administering magnesium sulfate postoperatively did not.

A systematic review with meta-analysis published by Peng etal. in 2018 studied intravenous magnesium sulfate for postoperative analgesia specifically in orthopedic surgery patients, included 11 RCTs with a total patient population of 535, and concluded that magnesium could reduce postoperative analgesic consumption.18 Two studies used a bolus dose, seven studies used a bolus and infusion, and two studies used only an infusion. The two studies with a bolus dose used $50 \mathrm{mg} / \mathrm{kg}$ at the beginning in one study and 1gram at the end of surgery in the other study. The studies using a bolus and infusion utilized the standard $30-50 \mathrm{mg} / \mathrm{kg}$ bolus followed by $8-15 \mathrm{mg} / \mathrm{kg} /$ hour during the procedure. For the infusion only studies, one study used $8 \mathrm{mg} / \mathrm{kg} /$ hour during the procedure and the other study used $50 \mathrm{mg} / \mathrm{kg}$ during suturing. Interestingly, when the pain ratings for the magnesium group were analyzed in each individual study, every study showed overall decreased postoperative pain scores. The visual analog scale (VAS) pain score was significantly lower at hours 2, 4, 6, and 12 but not for hour 8 postoperatively. The varied dosing regimens could have had an impact on which studies had significantly lower pain scores. For example, the previous study by Arumugam noted that a bolus dose and infusion provided greater analgesic effect than a single bolus or a postoperative infusion. In addition to the above meta-analyses, seven randomized controlled trials and one review article that were published between 2013 through 2018 which also provided evidence that intravenous magnesium sulfate reduces postoperative pain scores using various dosing regimens. Six of the studies utilized boluses as their main intervention, while the remaining study utilized a $15 \mathrm{mg} / \mathrm{kg} /$ hour continuous intraoperative infusion [18-26]. A limited number of studies investigated magnesium sulfate in conjunction with either ketamine or lidocaine infusions for decreasing postoperative pain. A study by Stessel et al. used $0.2 \mathrm{mg} / \mathrm{kg}$ of ketamine and $15 \mathrm{mg} / \mathrm{kg}$ of magnesium for bolus followed by 24-hour continuous infusions of $2 \mu \mathrm{g} / \mathrm{kg} / \mathrm{min}$ of ketamine and $5 \mathrm{mg} / \mathrm{kg} / \mathrm{min}$ of magnesium [27]. This study included 167 patients undergoing lower abdominal open surgery at a university hospital. The data did not show any statistical significance between the study groups and control group, but this could be attributed to the study having to be terminated prematurely due to multiple organizational problems. The second study by Jabbour et al. used a post-induction dose of $0.2 \mathrm{mg} / \mathrm{kg}$ of ketamine and $50 \mathrm{mg} / \mathrm{kg}$ of magnesium along with a continuous infusion of $0.15 \mathrm{mg} / \mathrm{kg} /$ hour of ketamine and $8 \mathrm{mg} /$ $\mathrm{kg} /$ hour of magnesium until the patients were extubated [28]. While the postoperative VAS scores were not statistically different from the control group, cumulative morphine consumption, first night sleep quality, and satisfaction scores were significantly better in the ketamine and magnesium group. The researches useda higher bolus and infusion dose of magnesium that fell within the most common dosing range from recent studies that showed a statistically significant decrease in postoperative pain scores.

In addition to a decrease in postoperative pain, there are potential additional benefits from using intravenous magnesium sulfate. Patients receiving magnesium sulfate require less nondepolarizing neuromuscular blocking agents due to magnesium acting as a calcium channel blocker at the presynaptic nerve terminal, which causes a decrease in acetylcholine release at the motor endplate [26-29]. Blocking of calcium channels by magnesium sulfate has also been shown to cause smooth muscle relaxation that leads to decreased systemic vascular resistance and increased bronchodilation [30,31]. One RCT that utilized magnesium sulfate in patients undergoing liver transplants and another RCT that used magnesium sulfate in patients undergoing coronary pulmonary artery bypass grafting showed a decrease in postoperative mechanical ventilatory time [21,32]. Lastly, the meta-analysis by De Oliveira (2013) also reported a decrease in postoperative shivering, however other meta-analyses did not report this [15]. None of the meta-analyses or RCTs reported any events of hypermagnesemia or toxicity. There were also no reports of delayed emergence. The two potential side effects reported at a higher rate than placebo were bradycardia and hypotension which are most likely the result of magnesium's calcium channel blocking effect $[14,25]$. The only meta-analysis to provide data regarding adverse side effects was by Albrecht et al. in 2012 which included the data from six RCTs [14]. Compared to placebo in those six studies, hypotension occurred in $22 / 116$ (18.9\%) of magnesium patients compared to $14 / 117$ (11.9\%) in the placebo group, while bradycardia in the magnesium group was $32 / 296$ (10.8\%) compared to $16 / 294$ (5.4\%) of placebo patients [14]. IV administration of magnesium sulfate appears to be very safe in patients with adequate kidney function. Since regulation of magnesium is controlled by the kidney, hypermagnesemia would 
be possible with a kidney function deficit. Values for normal total serum magnesium concentrations vary slightly depending on the reference but will range closely to $0.7-1.1 \mathrm{mmol} / \mathrm{L}, 1.4-2.2 \mathrm{mEq} / \mathrm{L}$, or $1.7-2.6 \mathrm{mg} / \mathrm{dL}$ with $30 \%$ being bound to albumin [33]. The kidney can filter 2,000-2,400 mg of magnesium per day with $96 \%$ of filtered magnesium being reabsorbed in the proximal tubule (10-30\%) and the thick ascending limb (40-70\%) [33]. Kidney disease does impact the filtration and reabsorption of magnesium. With moderate kidney disease, loss of full glomerular filtration is offset by a decreased reabsorption rate of magnesium leading to an increased excretion rate [34]. This compensatory mechanism becomes ineffective when creatinine clearance falls below $30 \mathrm{~mL} / \mathrm{min}$ which can precipitate hypermagnesemia [34]. Hypermagnesemia occurs when serum magnesium levels are greater than $2.6 \mathrm{mg} / \mathrm{dL}$ (1.05mmol/L) [35]. As hypermagnesemia worsens, symptoms get progressively worse. Therefore, IV magnesium sulfate should not be given to patients with a creatinine clearance less than $30 \mathrm{~mL} / \mathrm{min}$ and should be used with caution in patients with kidney function that is below normal. If a patient displays signs and symptoms of hypermagnesemia (Figure 1), treatment should consist of $10-20 \mathrm{~mL}$ of $10 \%$ calcium gluconate IV.35 Also, furosemide can be administered if the patient has adequate kidney function and the last resort would be hemodialysis [35]. Another patient population that IV magnesium sulfate should not be given to, unless directed by an obstetrician, are pregnant women. While IV magnesium sulfate is routinely utilized to treat pre-eclampsia and eclampsia in pregnant patients, the benefits of decreased postoperative pain do not outweigh the risks. IV magnesium should not be used perioperatively because IV magnesium is a tocolytic, via smooth muscle relaxation, and will cross the placenta affecting the fetus [36]. Magnesium sulfate is also contraindicated in hypermagnesemia, hypocalcemia, heart block, and myocardial damage [37-40].

\begin{tabular}{|c|l|}
\hline $6-12 \mathrm{mg} / \mathrm{dL}(2.5-5 \mathrm{mmol} / \mathrm{L})$ & $\begin{array}{l}\text { Prolonged PR interval } \\
\text { Widening of QRS complex } \\
\text { Increased T-wave amplitude }\end{array}$ \\
\hline $12 \mathrm{mg} / \mathrm{dL}(5 \mathrm{mmol} / \mathrm{L})$ & $\begin{array}{l}\text { Hypotension } \\
\text { Respiratory depression } \\
\text { Narcosis }\end{array}$ \\
\hline$>15 \mathrm{mg} / \mathrm{dL}(6.0-7.5 \mathrm{mmol} / \mathrm{L})$ & Cardiac Arrest \\
\hline
\end{tabular}

Figure 1: Magnesium levels with associated signs and symptoms [35].

\section{Discussion}

Anesthesia providers are being compelled to learn to safely use non-opioid medications to decrease postoperative pain in an effort to decrease opioid purpose. However, many do not utilize magnesium sulfate for this use, even though they may be aware that it has been shown to decrease postoperative pain. This lack of utilization may be related to a lack of knowledge of how to properly and safely dose IV magnesium sulfate or to the lack of standardized IV magnesium sulfate dosing recommendations for decreasing postoperative pain. Increasing awareness of the other potential benefits of magnesium sulfate is also necessary to encourage anesthesia providers to utilize magnesium sulfate. These include decreased amount of non-depolarizing paralytic needed, bronchodilation, the possibility of decreased postoperative ventilatory time, and the possibility of decreased postoperative shivering with IV magnesium sulfate use. Confidence in utilizing this drug also requires being aware of the potential side effects of IV magnesium sulfate use. These potentially include the loss of deep tendon reflexes and muscle function, hypotension or bradycardia. Safe use includes knowing the signs and symptoms of hypermagnesemia in an intubated patient. This also includes the care of the obstetric patient that has already been on a magnesium infusion or a patient presenting for an emergency C-section with signs and symptoms of hypermagnesemia. Care givers need to understand the importance of checking magnesium levels and also knowing how to treat hypermagnesemia. Further research could be completed to determine how to help anesthesia providers increase their utilization of magnesium sulfate in the future to decrease postoperative pain.

\section{Conclusion}

There is a renewed focus on using alternative medicines to treat postoperative pain instead of opioids, due to the increasing number of deaths from opioid overdose. IV magnesium sulfate is a proven viable option to decrease postoperative pain, however it is currently being underutilized by anesthesia providers. The 
purpose of this review was to explore the evidence towards establishing more standardized IV magnesium sulfate dosing recommendations for decreasing postoperative pain. In summarizing the wide variation of dosing regimens that were studied and discussed in the data from five meta-analyses and 7 RCTs, a recommendation for the most effective and most utilized dosing regimen was determined. This included an intravenous bolus of 30-50mg/kg, given over 15-30 minutes at the beginning of the operation. This bolus may or may not then be followed with a continuous infusion of $6-15 \mathrm{mg} / \mathrm{kg} /$ hour, usually ending when the operation ends, but sometimes continuing through the recovery period. While IV administration of magnesium sulfate has proven to be very safe, infusions should not routinely be given to obstetric patients or in patients with renal failure. And lastly, if signs and symptoms of hypermagnesemia arise, treatment should consist of $10-20 \mathrm{~mL}$ of $10 \%$ calcium gluconate IV [35]. IV magnesium sulfate is a safe and effective alternative to opioids for post-operative pain control.

\section{Acknowledgement}

The following individuals should be acknowledged for their contributions in researching this topic: Tyson Trpkosh, BSN, SRNA (SRNA) and Kristin Turner BSN, SRNA, Missouri State University, School of Anesthesia

\section{Conflict of Interest}

No economic interest or any other conflict of interest exists for this author.

\section{References}

1. Drug overdose drug data. Center for Disease Control and Prevention.

2. Magnesium in the diet. Medline Plus.

3. Magnesium: Fact sheet for consumers. National Institutes of Health: Office of Dietary Supplements.

4. Magnesium: Fact sheet for health professionals. National Institutes of Health: Office of Dietary Supplements.

5. Rosanoff A, Weaver CM, Rude RK (2012) Suboptimal magnesium status in the United states: Are the health consequences underestimated. Nutr Rev 70(3): 153-164.

6. Lambe SD, Karmarkar SS, Naik PS, Patil AB (2016) Study of serum magnesium in surgical stress. Journal of Krishna Institute of Medical Sciences University 5(4).

7. Okusanya BO, Oladapo OT, Long Q, Lumbiganon P, Carroli G, et al. (2016) Clinical pharmacokinetic properties of magnesium sulfate in women with pre-eclampsia and eclampsia. BJOG 123(3): 356-366.

8. Kaye P, O'Sullivan L (2002) The role of magnesium in the emergency department. Emergency Medicine Journal 19: 288-291.

9. Mayer ML, Westbrook GL, Guthrie PB (1984) Voltage-dependent block by Mg2 of NMDA responses in spinal cord neurons. Nature. 309(5965): 261-263.

10. McCarthy RJ, Kroin JS, Tuman KJ, Penn RD, Ivankovich AD (1998) Antinociceptive potentiation and attenuation of tolerance by intrathecal co-infusion of magnesium sulfate and morphine in rats.
Anesth Analg 86(4):830-836.

11. Woolf CJ, Thompson SW (1991) The induction and maintenance of central sensitization is dependent on $\mathrm{N}$-methyl-D-aspartic acid receptor activation; implications for the treatment of post-injury pain hypersensitivity states. Pain 44(3): 293-299.

12. Nagelhout JJ, Plaus KL (2014) Nurse Anesthesia. $5^{\text {th }}$ Edn. St. Louis, MO: Elsevier.

13. Tramer MR, Schneider J, Marti RA, Rifat K (1996) Role of magnesium sulfate in postoperative analgesia. Anesthesiology 84(2): 340-347.

14. Albrecht E, Kirkham KR, Liu SS, Brull R (2013) Peri-operative intravenous administration of magnesium sulphate and postoperative pain: a meta-analysis. Anesthesia 68(1): 79-90.

15. De Oliveira GS, Castro-Alves LJ, Khan JH, McCarthy RJ (2013) Perioperative systemic magnesium to minimize postoperative pain. Anesthesiology 119(1): 178-190.

16. Guo BL, Lin Y, Hu W, Zhen CX, Bao-Cheng Z, et al. (2015) Effects of systematic magnesium on post-operative analgesia: Is the current evidence strong enough? Pain Physician 18(5): 405-418.

17. Arumugam S, Lau CSM, Chamberlain RS (2016) Perioperative adjunct magnesium decreases postoperative opioid requirements - A metaanalysis. Int J Clin Med 7(5):297-308.

18. Peng YN, Sung FC, Huang ML, Lin CL, Kao CH (2018) The use of intravenous magnesium sulfate on postoperative analgesia in orthopedic surgery. Medicine 97(50): 13583.

19. Haryalchi K, Abedinzade M, Khanaki K, Ghanaie MM, Zadeh FM (2017) Whether preventative low dose magnesium sulphate infusion has influence on postoperative pain perception and the level of serum beta-endorphine throughout the total abdominal hysterectomy. Rev Esp Anestesiol Reanim 64(7): 384-390.

20. Jarahzadeh MH, Harati ST, Babaeizadeh H, Yasaei E, Bashar FR (2016) The effect of intravenous magnesium sulfate on reduction of pain after abdominal hysterectomy under general anesthesia: a double-blind, randomized clinical trial. Electronic Physician 8(7):2602-2606.

21. Gucyetmez B, Atalan HK, Aslan S, Yazar S, Polat KY (2016) Effects of intraoperative magnesium sulfate administration on postoperative tramadol requirement in liver transplantation: A prospective, doubleblind study. Tranplant Proc 48(8): 2742-2746.

22. Kim JE, Shin CS, Lee YC, Lee HS, Ban M, Kim SY (2015) Beneficial effect of intravenous magnesium during endoscopic submucosal dissection for gastric neoplasm. Surg Endosc 29(12): 3795-3802.

23. Taheri A, Haryalchi K, Ghanaie MM, Arejan NH (2015) Effect of lowdose (single-dose) magnesium sulfate on postoperative analgesia in hysterectomy patients receiving balanced general anesthesia. Anesthesiol Res Pract 2015: 306145.

24. Kocman IB, Krobot R, Premuzic J, Stare R, Katalinic L, et al. (2013) The effect of preemptive intravenous low-dose magnesium sulfate on early postoperative pain after laparoscopic cholecystectomy. Acta Clin Croat 52(3): 289-294.

25. Moharari RS, Motalebi M, Najafi A, Zamani MM, Imani F, et al. (2013) Magnesium can decrease postoperative physiological ileus and postoperative pain in major non laparoscopic gastrointestinal surgeries: A randomized controlled trial. Anesth Pain Med 4(1) :12750.

26. Do S-H (2013) Magnsium: A versatile drug for anesthesiologists. Korean J Anesthesiol 65(1): 4-8.

27. Stessel B, Ovink JK, Theunissen HM, Kessels AG, Marcus MA, et al. (2013) Is s-ketamine with or without magnesium sulphate an alternative for postoperative pain treatment? Randomized study. Eur J Anaesthesiol 30(2): 91-93. 
28. Jabbour HJ, Naccache NM, Jawish RJ, Abou Zeid HA, Jabbour KB, et al. (2014) Ketamine and magnesium association reduces morphine consumption after scoliosis surgery: prospective randomized doubleblind study. Acta Anaesthesiol Scand 58(5): 572-579.

29. Ryu JH, Koo BW, Kim BG, Oh AY, Kim HH, et al. (2016) Prospective, randomized and controlled trial on magnesium sulfate administration during laparoscopic gastrectomy: effects on surgical space conditions and recovery profile. Surg Endosc 30(11): 4976-4984.

30. Bara M, Guiet-Bara A (2014) Magnesium regulation of Ca2 channels in smooth muscle and endothelial cells of human allantochorial cells. Magnes Res 14(1-2): 11-18.

31. Noppen M (2002) Magnesium treatment for asthma. Chest 122(2): 396-397.

32. Dabbagh A, Bastanifar E, Foroughi M, Rajaei S, Keramatinia AA (2013) The effect of intravenous magnesium sulfate on serum levels of N-terminal pro-brain natriuretic peptide (NT pro-BNP) in elective CABG with cardiopulmonary bypass. J Anesth 27(5): 693-698.

33. Blaine J, Chonchol M, Levi M (2015) Renal control of calcium, phosphate, and magnesium homeostasis. Clin J Am Soc Nephrol 10(7): 1257-1272.
34. Cunningham J, Rodriguez M, Messa P (2012) Magnesium in chronic kidney disease Stages 3 and 4 and in dialysis patients. Clinical Kidney J 5(1): 39-51.

35. Lewis JL (2018) Hypermagnesemia. Merck Manual Professional Version.

36. Greenberg MB, Penn AA, Whitaker KR, Kogut EA, El-Sayed YY, et al (2013) Effect of magnesium sulfate exposure on term neonates. J Perinatol 33(3): 188-93.

37. Vallerand AH, Sanoski CA, Deglin JH (2013) Davis's Drug Guide for Nurses. $13^{\text {th }}$ Edn. Philadelphia.

38. Gahart BL, Nazareno AR (2013) Intravenous Medications. $29^{\text {th }}$ Edn. St. Louis, MO: Elsevier.

39. Wren KR (2001) Learning from a nurse anesthetist perspective: A Qualitative Study. AANA J 69(4): 273-278.

40. Whittingham JR, Ruiter RA, Castermans D, Huiberts A, Kok G, et al. (2008) Designing effective health education materials: experiment pre-testing of a theory-based brochure to increase knowledge. Health Educ Res 23(3): 414-426.

\section{Your next submission with Juniper Publishers} will reach you the below assets

- Quality Editorial service

- Swift Peer Review

- Reprints availability

- E-prints Service

- Manuscript Podcast for convenient understanding

- Global attainment for your research

- Manuscript accessibility in different formats

( Pdf, E-pub, Full Text, Audio)

- Unceasing customer service

Track the below URL for one-step submission https://juniperpublishers.com/online-submission.php 